\title{
"Construindo uma comunidade global": análise crítica sobre as estratégias de tecnologização do discurso do Facebook
}

"Building a global community:" a critical analysis on Facebook's discourse technologization estrategies

"Construyendo una comunidad global": análisis crítico sobre las estrategias de tecnologización del discurso de Facebook

\section{Moab Duarte Acioli}

- Doutor em Saúde Pública pela Universidade Estadual de Campinas (Unicamp).

- Mestre em Antropologia Cultural pela Universidade Federal de Pernambuco (Unicap).

- Professor Adjunto do Centro de Ciências Biológicas e da Saúde da Unicap.

- Professor do Programa de Pós-Graduação em Ciências da Linguagem da Unicap.

- Membro do Comitê de Ética da Unicap.

- E-mail: moab.acioli@unicap.br

(9) João Guilherme de Melo Peixoto

- Doutor em Comunicação Social pela Universidade Federal de Pernambuco (UFPE).

- Mestre em Comunicação Social pela UFPE.

- Professor do Programa de Pós-Graduação em Indústrias Criativas da Unicap.

- Servidor público do Tribunal de Justiça de Pernambuco (TJPE).

- E-mail: joaogmpeixoto@gmail.com

Maria Eduarda Alves de Andrade

- Mestranda em Ciências da Linguagem pela Unicap.

- Graduada em Jornalismo pela mesma instituição.

- E-mail: meduardaandradec@gmail.com 


\section{Resumo}

Este trabalho tem como objetivo identificar como se dão os processos de tecnologização do discurso na sociedade contemporânea a partir da utilização das redes sociais digitais. Para isso, analisou-se o texto "Construindo uma Comunidade Global", do cocriador do Facebook, Mark Zuckerberg. Por meio da análise crítica do discurso, observou-se como se manifestam discursivamente as ideologias neoliberalistas cuja finalidade é manipular e controlar os indivíduos para que estes permaneçam conectados nas comunidades digitais.

\section{PALAVRAS-CHAVE: ANÁLISE CRÍTICA DO DISCURSO • TECNOLOGIZAÇÃO DO DISCURSO • REDES SOCIAIS DIGITAIS • FACEBOOK.}

\section{Abstract}

This study aims to observe how the processes of technologization of discourse occurs in contemporary society based on the use of online social networks. To this end, the letter "Building a Global Community," written by Mark Zuckerberg, Facebook's co-founder, was analyzed in the light of critical discourse analysis (CDA). The results evince the discursive manifestations of neoliberal ideologies, which seek to manipulate and control individuals as to keep them connected to digital communities.

KEYWORDS: CRITICAL DISCOURSE ANALYSIS • TECHNOLOGIZATION OF DISCOURSE・ONLINE SOCIAL NETWORKS• FACEBOOK.

\section{Resumen}

Este trabajo tiene como objetivo observar cómo se desarrollan los procesos de tecnologización del discurso en la sociedad contemporánea, a partir del uso de las redes sociales digitales. En este contexto, se analizó el texto "Construyendo una comunidad global", del cocreador de Facebook, Mark Zuckerberg. A partir del análisis crítico del discurso, se observó cómo se manifiestan discursivamente las ideologías neoliberalistas cuyo propósito es manipular y controlar a los individuos para que permanezcan conectados en comunidades digitales. 


\section{INTRODUÇÃO}

O

processo discursivo carrega uma série de outros discursos, e é necessário observar suas práticas inter-relacionadas constitutivas (Fairclough; Melo, 2012). Diversos discursos dialogam entre si, engendrando uma ordenação social das relações entre as formas de construir sentido. A concepção de tais práticas ocorre em duas formas: 1) prática discursiva, vinculada ao processo de produção, distribuição e consumo do texto; 2) prática social, relacionada principalmente à ideia de poder e ideologia (Fairclough, 2019).

É possível afirmar que, entre os efeitos da globalização, os indivíduos passaram a ter suas vidas caracterizadas pelo controle. Dessa forma, a tecnologização do discurso surge como um aspecto da ordem do discurso moderno. Sobre isso, pontua Fairclough (2019):

As tecnologias discursivas estabelecem uma ligação íntima entre o conhecimento sobre linguagem, discurso e poder. Elas são planejadas e aperfeiçoadas com base nos efeitos antecipados mesmo nos mais apurados detalhes de escolhas linguísticas no vocabulário, na gramática, na entonação, na organização do diálogo, entre outros, como também na expressão facial, o gestor, a postura, os movimentos corporais. Elas produzem mudança discursiva mediante um planejamento consciente. Isso implica acesso de parte dos tecnólogos ao conhecimento sobre linguagem, o discurso e a semiose, e ainda ao conhecimento psicológico. (p.276)

A propagação de redes sociais digitais (Recuero, 2019) aponta para uma reconfiguração dos processos comunicacionais a partir de uma lógica de dispersão e do compartilhamento. Ressalta-se, entre essas ferramentas, o Facebook, rede social mais utilizada no mundo, com mais de 3 bilhões de usuários ativos (Nossa..., 2021). Criado em 2003 por Mark Zuckerberg, Dustin Moskovitz e Chris Hughes, pode-se destacar, entre os princípios anunciados no site da empresa: criar conexão e comunidade, servir a todos, manter as pessoas seguras e proteger a privacidade e promover oportunidade econômica (Nossa..., 2021).

Suas funcionalidades atendem a uma demanda específica da contemporaneidade, a saber:

[...] como muitos sites de rede social, é uma ferramenta apropriada simbolicamente para construir o espaço social no cotidiano dos atores, gerando práticas que ressignificam seus usos. Dentre essas apropriações, está a conversação. Essa prática, geralmente focada nas trocas que acontecem entre falantes, passa a ser um uso dessas ferramentas, que são adaptadas para ferramentas primariamente textuais, muitas vezes assíncronas, através da criação de convenções e novos sentidos entre os atores. E esses sentidos são constantemente adaptados e reconstruídos pelas redes sociais que estão em movimento na ferramenta, pela dinâmica sistêmica que envolve esses grupos. (Recuero, 2012, p.114)

Atento aos impactos do compartilhamento do discurso na construção das práticas sociais, o presente artigo tem como objetivo identificar o processo de tecnologização do discurso (Fairclough, 2019) na sociedade contemporânea, a partir das redes sociais digitais. Para isso, analisará o texto "Building Global Community" (Zuckerberg, 2017), de autoria do co-criador do Facebook, Mark Zuckerberg. Existem as seguintes perguntas-chave: Qual a relação de sentido entre redes sociais digitais e a tecnologização do discurso? Qual o papel do Facebook nesse processo? Quais as práticas sociais envolvidas com as práticas discursivas presentes no Facebook?

A análise será elaborada a partir do modelo tridimensional do discurso, desenvolvido por Norman Fairclough. Sua adoção implica uma investigação dos eventos através de uma triangulação dialética: texto, prática discursiva e prática social. Em 
face da condição crítica de sua proposta, o analista deve buscar estruturas que busquem romper os campos vagos de sua investigação, a partir de uma Teoria Social do Discurso (Fairclough, 2019).

\section{REFERENCIAL TEÓRICO}

A consolidação da tecnologização do discurso tem uma ligação direta com o neoliberalismo, colocado por Harvey (2008) do seguinte modo:

Teoria das práticas político-econômicas que propõe que o bem-estar humano pode ser melhor promovido liberando-se as liberdades e capacidades empreendedoras individuais no âmbito de uma estrutura institucional caracterizada por sólidos direitos à propriedade privada, livres mercados e livre comércio. (p.68)

A análise crítica do discurso (ACD) estuda os discursos, quando estrategicamente compartilhados em relações de poder, a gerarem efeitos sociais. Trata-se de uma abordagem teórico metodológica que investiga a exploração do domínio como forma de controle de crenças e ações das pessoas entre grupos dominantes por meio dos respectivos processos discursivos (Van Dijk, 1999). Ela se atém às mudanças radicais da vida social contemporânea, avaliando o papel que a semiose manifesta na constituição dos processos de transformação discursiva e social e nas relações com outros elementos coletivos dentro de sua rede de práticas (Fairclough; Melo, 2012).

Diante da relevância do poder para a compreensão dos efeitos dos processos discursivos, destaca-se, no campo da ACD, o conceito de hegemonia, defendido por Gramsci (1971) como uma forma de funcionamento do estado ético, no qual a construção de uma classe dirigente deve se manter por meio do consentimento das massas, o que justifica a importância de uma implementação na direção cultural e ideológica dos sujeitos. Igualmente relevante é o conceito de ideologia, comentado por Thompson (1995) como um sistema de crenças ou formas e práticas simbólicas, cuja construção do sentido no mundo social reforça posições distintas de controle entre pessoas e grupos.

Ao se estudar a relação entre poder e tecnologização do discurso, na perspectiva da ACD, é relevante o contexto, uma vez que se trata de uma estratégia de controle e manipulação social que desempenha uma função de remodelagem das práticas discursivas através dos efeitos hegemônicos e ideológicos mais alargados que essas práticas podem ter (Fairclough, 2019). Keat e Abercrombie (1990) reforçam que a tecnologização do discurso é um dos aspectos da hegemonia para a reestruturação de subjetividade e identidades.

A partir dela, tenta-se elaborar uma reformulação entre os textos e as práticas discursivas e socioculturais (Fairclough, 2019). Por conseguinte, significa dizer que há um deslocamento de práticas de nível institucional para um nível transinstitucional, fazendo que crenças e valores compartilhados e implementados por instituições passem a ser de responsabilidade dos intitulados tecnólogos do discurso por meio de suas técnicas discursivas.

\section{METODOLOGIA}

A análise crítica do discurso se caracteriza mais como enfoque do que como método (Meyer, 2003). Através dela, são mapeadas as conexões entre relações de poder e recursos linguísticos. Localiza-se na interface entre a ciência linguística e a ciência social crítica, observando-se práticas de domínio e resistência por meio dos processos discursivos (Melo; Resende, 2010). Os dados são selecionados e organizados para a observação e avaliação do pesquisador, visando as respectivas inferências e 
interpretações (Meyer, 2003). Existem vários padrões de análise, sendo a ACD considerada um campo transdisciplinar que busca o entendimento de problemas sociais.

Sobre o corpus selecionado, o texto "Construindo uma Comunidade Global" foi publicado no dia 16 de fevereiro de 2017 pelo cocriador do Facebook em seu perfil na rede. Trata-se de uma carta aberta aos seus usuários, respondendo às acusações de que a ferramenta estaria incentivando o compartilhamento de fake news e discurso de ódio.

\section{CATEGORIAS DE ANÁLISE}

As categorias analíticas foram construídas a partir das estratégias metodológicas do Quadro 1.

Quadro 1: Estratégias metodológicas da análise crítica do discurso

\begin{tabular}{|c|c|c|}
\hline $\begin{array}{c}\text { PARTE } 1 \\
\text { Definições iniciais (Dados) }\end{array}$ & $\begin{array}{l}\text { - Definição do contexto e problemáticas; } \\
\text { - Definição do objeto; } \\
\text { - Definição dos dados a serem } \\
\text { usados (seleção do corpus) }\end{array}$ & \multirow{2}{*}{$\begin{array}{l}\text { Definição das Unidades } \\
\text { de Análise } \\
\text { Organização em categorias } \\
\text { definidas a priori }\end{array}$} \\
\hline $\begin{array}{c}\text { PARTE } 2 \\
\text { Análises preliminares }\end{array}$ & $\begin{array}{l}\text { - Coleta dos dados (primeira análise preliminar); } \\
\text { - Transcrição (segunda análise preliminar) } \\
\text { - Organização dos dados e análise preliminar } \\
\text { aprofundada: Leitura flutuante de todo o corpus } \\
\text { e Organização em categorias definidas a priori }\end{array}$ & \\
\hline \multirow[t]{2}{*}{$\begin{array}{l}\text { PARTE } 3 \\
\text { Análises }\end{array}$} & $\begin{array}{l}\text { Análise textual: vocabulário, } \\
\text { gramática, coesão e estrutura textual. } \\
\text { Análise de Práticas discursivas: } \\
\text { produção, distribuição e consumo de discursos. } \\
\text { Análise de Prática Social: aspectos } \\
\text { ideológicos e hegemônicos. }\end{array}$ & $\begin{array}{l}\text { Definição das Unidades } \\
\text { de Análise } \\
\text { Desvelar de Categorias Emergentes }\end{array}$ \\
\hline & RESULTADOS & \\
\hline
\end{tabular}

Fonte: Adaptado de Abdalla e Altaf (2018).

Dessa forma, a análise se fundamentou na análise textual - vocabulário e estrutura textual -, nas práticas discursivas e na prática social-aspectos ideológicos e hegemônicos.

\section{RESULTADOS}

Em relação ao gênero textual, observa-se que é uma carta aberta, considerada como domínio público, com o objetivo de divulgação para um grande grupo (Dionísio; Machado; Bezerra, 2007). 0 espectador é o principal alvo de sua argumentação, sendo persuadido a concordar com a tese defendida, que pode ser considerada uma manipulação cognitiva (Oliveira; Zanutto, 2017). 0 título em gerúndio expressa uma atividade em construção. Por fim, a estrutura do texto apresenta uma introdução e mais cinco tópicos que serão analisados a seguir. 


\title{
INTRODUÇÃO TEXTUAL
}

A Carta está endereçada para a "nossa" comunidade. 0 pronome possessivo denota uma visão de pertencimento tanto do autor do texto como do suposto leitor a uma determinada comunidade humana, chamada pelo Facebook de comunidade global. Zuckerberg (2017) escreve:

\begin{abstract}
Em nossa jornada para conectar o mundo, frequentemente discutimos produtos que estamos construindo e atualizações sobre nossos negócios. (grifo do autor) Hoje quero focar na questão mais importante de todas: estamos construindo o mundo que todos queremos? (grifo nosso) A história é a história de como aprendemos a nos reunir em números cada vez maiores - de tribos a cidades e nações. Em cada etapa, construímos infraestrutura social como comunidades, mídia e governos para nos capacitar a alcançar coisas que não conseguiríamos por conta própria. Hoje estamos perto de dar nosso próximo passo. Nossas maiores oportunidades agora são globais - como espalhar prosperidade e liberdade, promover paz e compreensão, tirar pessoas da pobreza e acelerar a ciência. Nossos maiores desafios também precisam de respostas globais - como acabar com o terrorismo, combater as mudanças climáticas e prevenir pandemias (grifo nosso). 0 progresso agora requer que a humanidade se reúna não apenas como cidades ou nações, mas também como uma comunidade global (grifo nosso) [...] Podemos não ter o poder de criar o mundo que desejamos imediatamente, mas todos podemos começar a trabalhar no longo prazo hoje. Em tempos como estes, a coisa mais importante que nós no Facebook podemos fazer é desenvolver a infraestrutura social para dar às pessoas o poder de construir uma comunidade global que funcione para todos nós.
\end{abstract}

De início, é possível identificar uma associação semântica ao mencionar um debate sobre produtos e negócios, apresentando uma ordem do discurso (Foucault, 1996) neoliberalista. 0 modelo de negócio do Facebook valoriza a perspectiva econômica, que passa a funcionar como uma infraestrutura relacionada a uma superestrutura ideológica e política que acompanha a dinâmica histórica do capitalismo (Silveira, 2009).

Outra associação vincula global e liberdade, na qual o Facebook se responsabiliza pela promoção de atividades como a paz, o fim da pobreza e a evolução da ciência. Desse modo, tendo em vista que se trata de um empreendimento caracterizado pelo individualismo e por seu interesse nos sólidos direitos à propriedade privada, livres mercados e livre comércio, há uma evidente contradição dialética, histórica e social (Triviños, 1987).

Zuckerberg (2017) ainda reforça o compromisso social de sua empresa ao escrever sobre o mundo que queremos. Considerando, na perspectiva da ACD, o conceito de interdiscurso como a presença de outros textos no texto (Fairclough; Melo, 2012), a ordem discursiva neoliberal continua presente como projeto de comunidade global.

Por fim, o autor grifa o texto, destacando o compromisso do Facebook em desenvolver uma infraestrutura social visando construir uma comunidade global que funcione para todos. Essa infraestrutura social estaria fundamentada em uma colonização do mundo da vida (Habermas, 2014), que, em um nível macro, é formado pelas organizações sociais e, em um nível micro, pelas organizações comunitárias onde os sujeitos vivem a cotidianidade. Ela se forma, segundo o autor, por uma comunidade de apoio segura, informada, engajada cívica e inclusiva.

\section{COMUNIDADE DE APOIO}

No interior de uma comunidade global existem milhões de subcomunidades, cuja estrutura social fornece esperança e propósito, funcionando como importante suporte emocional e espiritual. Trata-se do sentimento de pertencimento social, definido por 
Tavares (2014) como uma condição humana universal, pela qual todos os grupos e indivíduos lutam incessantemente, ao mesmo tempo que sofrem quando não a alcançam. Nesse sentido:

Nosso objetivo é fortalecer as comunidades existentes, ajudando-nos a reunir tanto on-line quanto off-line, além de nos permitir formar comunidades completamente novas, transcendendo a localização física. Quando fazemos isso, além de nos conectarmos on-line, reforçamos nossas comunidades físicas ao nos reunirmos pessoalmente para apoiarmos uns aos outros. Uma sociedade saudável precisa dessas comunidades para apoiar nossas necessidades pessoais, emocionais e espirituais. Em um mundo onde essa infraestrutura social física está em declínio, temos uma oportunidade real de ajudar a fortalecer essas comunidades e 0 tecido social de nossa sociedade. (Zuckerberg, 2017, grifo nosso)

Ao fazer uma comparação entre o velho (off-line) e o novo (on-line), o autor recorre a ao que Thompson (1995) intitula como meio de manifestação da ideologia, especificamente a fragmentação e diferenciação. A partir do momento em que escreve, ocupando a posição de fundador e gerenciador do Facebook, Zuckerberg (2017) exerce uma relação de dominação para com seus usuários, os leitores da carta. Desse modo, ele passa a inviabilizar transformações e forças de oposição aos seus interesses, estimulando a segregação entre o virtual e o presencial.

Tal estratégia é reforçada ao longo de seu discurso, no qual coloca o Facebook como ferramenta central para que os indivíduos passem a retomar suas vidas em comunidade. No entanto, tendo em vista o contexto da pandemia da covid-19, é válido questionar se uma comunidade tecnologizada não poderá vir a ocupar o espaço social significativo das comunidades físicas, levando em consideração, a longo prazo, a falta de interesse de seus usuários em viver socialmente. Nesse ponto, podemos destacar aspectos atrelados ao controle, à vigilância e à concentração de informações por parte de ações algorítmicas definidas por Pariser (2012) como "filtro bolha".

São mecanismos de previsão que criam e refinam constantemente uma teoria sobre quem somos e sobre o que vamos fazer ou desejar a seguir. Juntos, esses mecanismos criam um universo de informações exclusivo para cada um de nós - o que passei a chamar de bolha dos filtros - que altera fundamentalmente o modo como nos deparamos com ideias e informações. (p.11)

Zuckerberg (2017) naturaliza ainda o fato de que as comunidades sociais estão ameaçadas, o que se denomina estratégia de manifestação ideológica de reificação (Thompson, 1995). Todavia, não se pode desconsiderar que o fortalecimento das redes sociais digitais, por sua vez, faz parte do processo de globalização, que tem como característica a destruição das comunidades locais.

\section{COMUNIDADE SEGURA}

Para uma comunidade segura, é necessário um grupo que ajude a reconstrução dos prejuízos e das perdas após danos, além de preveni-los, em primeiro lugar. As ameaças como o terrorismo, desastres naturais, doenças, crises de refugiados e mudanças climáticas estão cada vez mais globais, diferentemente da infraestrutura para nos proteger.

Ao discutirmos como manter nossa comunidade segura, é importante enfatizar que parte de manter as pessoas seguras é proteger a segurança e a liberdade individuais (grifo do autor). Somos fortes defensores da criptografia e a incorporamos nas maiores plataformas de mensagens do mundo - WhatsApp e Messenger (grifo nosso). Manter nossa comunidade segura não exige comprometer a privacidade. Desde a construção da criptografia de ponta a ponta no WhatsApp, reduzimos o spam e o conteúdo malicioso em mais de $75 \%$. 0 caminho a seguir é reconhecer que uma comunidade global precisa de infraestrutura social para nos 
manter a salvo de ameaças em todo o mundo, e que nossa comunidade está posicionada de forma única para prevenir desastres, ajudar durante crises e reconstruir depois (grifo nosso). (Zuckerberg, 2017)

Zuckerberg (2017) relaciona a segurança dos usuários ao controle que o Facebook sobre seus dados. Essa fiscalização não inviabiliza a liberdade individual de cada sujeito. Inicialmente, destaca-se novamente o interdiscurso neoliberal, em que 0 individualismo é defendido como o motor da sociedade (Silveira, 2009). 0 autor se coloca como forte defensor da criptografia', já incorporada em ferramentas como o WhatsApp e o Messenger, também sob seu domínio.

Existe uma falsa sensação de privacidade e confidencialidade, haja vista que a marca tem acesso total às informações criadas e compartilhadas nas redes. Trata-se de uma simulação discursiva com fundamentos estratégicos e instrumentais de significados interpessoais e práticas discursivas (Fairclough, 2019). Por meio da informalidade de suas técnicas, Zuckerberg (2017) busca manter o controle das intituladas comunidades digitais a partir da convencionalização presente em seu discurso.

\section{COMUNIDADE INFORMADA}

Uma comunidade informada tem como característica o compartilhamento de ideias. No entanto, é preciso ficar atento à fragmentação da realidade a partir de dois problemas. 1) a diversidade de pontos de vista que formam as bolhas de filtro; e 2) as fake news, cujo combate necessita de precisão das informações. É este o comentário de Zuckerberg (2017):

Conectar todos à internet também é necessário para construir uma comunidade informada. Para a maioria das pessoas em todo o mundo, o debate não é sobre a qualidade do discurso público, mas se eles têm acesso às informações básicas de que precisam, muitas vezes relacionadas à saúde, educação e empregos. Por fim, quero enfatizar que a grande maioria das conversas no Facebook são sociais, não ideológicas. (grifo nosso)

A noção de comunidade informada requer que a sociedade esteja conectada à internet, consequentemente, em sua rede social digital. Todavia, existem questionamentos. 0 primeiro refere-se a quem são "todos" os sujeitos de interesse para 0 Facebook? Não se pode descartar a existência da miséria e de doenças, e se coloca a inclusão digital como uma política tecnológica em prioridade. É possível, mais uma vez, interpretar a presença de um interdiscurso neoliberal com ideologia de mercado (Fairclough, 2019).

Em tempos em que o debate sobre o fomento de fake news é evidenciado, Zuckerberg (2017) deixa subentender uma certa irrelevância quanto à checagem das notícias compartilhadas no Facebook, ao mesmo tempo que descredencia o papel da imprensa. Seu discurso carrega uma ideologia utilitarista norte-americana, em que determinada situação/atividade só se torna importante quando tende a aumentar e beneficiar certos grupos ou sujeitos (Silveira, 2018).

Zuckerberg (2017) também reforça que a grande maioria das conversas no Facebook são sociais, sem cunho político. Thompson (1995), por sua vez, esclarece que o social por si só já é ideológico, ou seja, até mesmo uma alienação faz parte de um pensamento com juízo de valor. Assim sendo, os discursos presentes na rede social digital são formulados com base nas formas simbólicas presentes nos contextos sociais que circulam em torno do mundo social, objetivando o controle por parte dos sujeitos.

1 Prática de codificação e de decodificação de dados, a partir da aplicação de um algoritmo. Os dados passam a ter um formato diferente do formato diferente dificultando a respectiva leitura. 


\section{COMUNIDADE ENGAJADA CÍVICA}

Para o desenvolvimento de uma comunidade engajada cívica é preciso que a população esteja inserida e interessada nos processos políticos existentes: votação, manifestação, organizações, entre outras. Desse modo, em seu texto, Zuckerberg (2017) explicita como o Facebook poderá ser capaz de promover um novo progresso de inclusão social nas tomadas de decisões coletivas:

\footnotetext{
Diariamente, as pessoas usam suas vozes para compartilhar seus pontos de vista de maneiras que podem se espalhar pelo mundo e se transformar em movimentos. A Marcha das Mulheres é um exemplo disso, onde uma avó conectada à internet escreveu um post que levou suas amigas a iniciar um evento no Facebook que acabou se transformando em milhões de pessoas marchando em cidades ao redor do mundo. Dar voz às pessoas é um princípio com o qual nossa comunidade está comprometida desde que começamos. À medida que buscamos construir a infraestrutura social para uma comunidade global, trabalharemos na construção de novas ferramentas que incentivem o engajamento cívico consciente. (grifo nosso)
}

Não se pode ignorar que as vozes supostamente "empoderadas" pelo Facebook são hegemonicamente controladas por uma empresa. Pedro (1998) explica que a hegemonia se forma também nas práticas discursivas das instituições e organizações, podendo seus discursos encerrar ou propagar ideologias naturalizadas (Thompson, 1995). Dessa forma, ao se referir ao Facebook como uma organização, Zuckerberg (2017) passa a modificar a função da ferramenta na vida dos usuários, de modo a naturalizar o controle que obtém entre eles.

Existem efeitos negativos dessa prática de apropriação do discurso. 0 autor sugere que a plataforma permite que o sujeito tenha voz, ou seja, diz que, caso este não estivesse conectado, estaria fora daquilo que se apresenta como construção de mundo. Na perspectiva da análise crítica do discurso (Fairclough, 2019), o posicionamento de Zuckerberg (2017) representa implicitamente uma segregação dos sujeitos, com a não participação no Facebook implicando uma desconexão com a realidade social.

\section{COMUNIDADE INCLUSIVA}

A construção de uma comunidade global exige uma participação dos sujeitos na governança dos seus grupos sociais, segundo 0 autor da carta. Subtende-se, portanto, que os processos atuais não são suficientemente participativos. Por isso, Zuckerberg (2017) comenta:

O Facebook não é apenas tecnologia ou mídia, mas uma comunidade de pessoas. Isso significa que precisamos de Padrões da Comunidade que reflitam nossos valores coletivos sobre o que deve e o que não deve ser permitido. [...] Muitos de nós defendemos a união de pessoas e a conexão do mundo. Espero que tenhamos o foco para ter uma visão de longo prazo e construir a nova infraestrutura social para criar o mundo que queremos para as gerações vindouras. É uma honra estar nesta jornada com você. Obrigado por fazer parte desta comunidade e por tudo que você faz para tornar o mundo mais aberto e conectado. (grifo do autor)

Para defender as práticas de inclusão promovidas pelo Facebook, o Zuckerberg considera que a rede social é menos tecnológica do que uma comunidade. Tönnies (1947) esclarece que uma relação comunitária diz respeito a toda a vida social de conjunto, íntima, interior e exclusiva (micro); enquanto a sociedade se constitui justamente como a sociabilidade do domínio público, do mundo exterior (macro). Desse modo, atentos às características sociológicas acima, o Facebook se coloca como uma comunidade de fala heterogênea (Labov, 1972), na qual os usuários devem permanecer unidos apesar das diferenças de seus contextos sociais. 
A partir da identificação dos valores e normas compartilhados entre seus usuários, Zuckerberg (2017) sinaliza seu interesse em criar uma conexão com o mundo, trazendo um interdiscurso de ordem global. Castells (1999) caracteriza a ideia de globalização a partir da integração do mundo em redes globais de instrumentalidade. Assim, o Facebook fomenta a criação de processos de mudança com um impacto substancial sobre as cidades e o espaço.

Por fim, é retomada a ideia central de construção de uma infraestrutura social, caracterizada pela criação das comunidades de apoio, segurança, informação, engajamento cívico e inclusão, apresentadas por ele ao longo da carta. Diante disso, fica claro o interesse de Mark Zuckerberg em exercer uma relação de poder cultural, político, mercadológico, midiático, científico, entre outros, justificando a leitura de seu texto a partir da perspectiva da ACD.

\section{CONSIDERAÇÕES FINAIS}

Conforme visto, a sociedade contemporânea se caracteriza pelo controle. A partir do desenvolvimento das ferramentas digitais de comunicação, o discurso vem sendo cada vez mais tecnologizado. Trata-se de uma expansão do discurso estratégico para obter novos domínios, o que se reflete na apropriação da conversa pelas instituições e em seu investimento em conteúdo político e ideológico (Fairclough, 2019).

Trazendo essa discussão para o Facebook, a partir da análise realizada, pode-se observar como Zuckerberg (2017) manipula seus usuários por meio de estratégias discursivas. Em se tratando de uma rede social digital com mais de 3 bilhões de pessoas conectadas, fundada e administrada por ele, o texto publicado em seu perfil passa a ter um impacto social e publicidade ainda maiores, sendo notícia na imprensa mundial e alcançando compartilhamentos inatingíveis em comparação com os conteúdos dos demais usuários.

Trazendo o interdiscurso, o autor passa a descredenciar o papel das instituições sociais, apontando o Facebook como ferramenta capaz de reconstituir o interesse da sociedade em viver coletivamente nas comunidades físicas. Assim, tornase mais eficaz a perpetuação e reprodução de dimensões culturais e ideológicas da hegemonia, o que significa dizer que os sujeitos são manipulados para compactuar com crenças e valores semelhantes, mantendo-se em suas comunidades virtuais. Essas estratégias são reforçadas pela tecnologização do discurso na sociedade contemporânea, e o Facebook ocupa um lugar chave, reformulando o próprio conceito de grupos comunitários.

Trata-se, portanto, de uma sofisticação do controle ideológico da globalização baseada no neoliberalismo, em que o sentido de privatização econômica "invade" o espaço privado da intimidade comunitária, remodelando o sentido do espaço público.

Ademais, este trabalho aponta para novas possibilidades de pesquisa acerca das disputas de sentido dos temas aqui abordados, a exemplo de como a ideologia neoliberal opera perante discussões sobre o fenômeno das fake news e os processos de responsabilização das próprias plataformas digitais de comunicação perante a sociedade.

Por fim, é válido ressaltar ainda a necessidade de fomentar investigações sobre o papel dos discursos na reformulação das práticas sociais a partir de seu compartilhamento em ambientes digitais. 


\section{REFERÊNCIAS}

ABDALLA, Márcio Moutinho; ALTAF, Joyce Gonçalves. Análise crítica do discurso em administração/gestão: sistematização de um framework metodológico para o modelo tridimensional de Norman Fairclough. In: ENCONTRO DE ENSINO E PESQUISA EM ADMINISTRAÇÃO, 18., 2018, Porto Alegre. Anais [...]. Porto Alegre: Anpad, 2018. p.1-12.

CASTELLS, Manuel. A Era da Informação. Economia, sociedade e cultura. São Paulo: Paz e Terra, 1999.

DIONÍSIO, Angela P.; MACHADO, Anna R.; BEZERRA, Maria A. Gêneros textuais e ensino. Rio de Janeiro: Lucerna, 2007.

FAIRCLOUGH, Norman. Discurso e mudança social. 2.ed. Brasília, DF: Ed. UnB, 2019.

FAIRCLOUGH, Norman; MELO, Iran Ferreira de. Análise crítica do discurso como método em pesquisa social científica. Linha D'Água, São Paulo, v.25, n.2, p.307-329, 2012.

FOUCAULT, Michel. Ordem do discurso. 24.ed. São Paulo: Loyola, 1996.

GRAMSCI, Antonio. Selections from the prison notebooks. London: Lawrence and Wishart, 1971.

HABERMAS, Jürgen. Conhecimento e interesse. São Paulo: Editora Unesp, 2014.

HARVEY, David. El neoliberalismo como destrucción creativa. Apuntes del Cenes, Bogotá, v.27, n.45, p.10-34, 2008.

KEAT, Russell; ABERCROMBIE, Nicholas. Enterprise culture. London: Routledge, 1990.

LABOV, William. Language in the inner city. studies in the Black English vernacular. Harrisburg: University of Pennsylvania Press, 1972.

MEYER, Michel. Entre la teoría, el método y la política: la ubicación de los enfoques relacionados con el ACD. In: WODAK, Ruth; MEYER, Michel. Métodos de análisis crítico del discurso. Barcelona: Gedisa, 2003. p.35-59.

NOSSA missão. Facebook, São Paulo, 2021. Disponível em: https://about.fb.com/br/company-info/. Acesso em: 25 abr. 2021.

OLIVEIRA, Neil Armstrong Franco de; ZANUTTO, Flávia. 0 gênero Carta Aberta: da interlocução marcada à interlocução esperada. In: ANTONIO, Juliano Desiderato; NAVARRO, Pedro (org.). Gêneros textuais em contexto de vestibular. Maringá: Eduem, 2017. p.133-151.

PARISER, Eli. O filtro invisível: o que a internet está escondendo de você. Rio de Janeiro: Zahar, 2012.

PEDRO, Emília Ribeiro. Análise crítica do discurso: uma perspectiva sociopolítica e funcional. Alfragide: Caminho, 1998.

RECUERO, Raquel; GRUZD, Anatoliy. Cascatas de fake news políticas: um estudo de caso no Twitter. Galáxia, São Paulo, n.41, p.31-47, 2019. 
RECUERO, Raquel. 0 capital social em rede: como as redes sociais na internet estão gerando novas formas de capital social. Contemporânea, Salvador, v.10, n.3, p.597-617, 2012.

RESENDE, Viviane de Melo; RAMALHO, Viviane C. Vieira Sebba. Análise de discurso crítica, do modelo tridimensional à articulação entre práticas: implicações teórico-metodológicas. Linguagem em (Dis)curso, Tubarão, v.5, n.1, p.185-208, 2010.

SILVEIRA, Éderson Luís; FÁTIMA, Welton da Silva de. Humanidades e a (des)ordem legislativa: análise do discurso do utilitarismo em sugestões sobre cursos universitários. In: CONGRESSO NACIONAL DE LINGUÍSTICA E FILOLOGIA, 22., 2018. Anais [...]. Rio de Janeiro: CiFEFiL, 2018. p.545-563.

SILVEIRA, Ramaís de Castro. Neoliberalismo: conceito e influências no Brasil - de Sarney a FHC. 2009. Dissertação (Mestrado em Ciência Política) - Universidade Federal do Rio Grande do Sul, Porto Alegre, 2009.

TAVARES, Rosana Carneiro. 0 sentimento de pertencimento social como um direito básico e universal. Cadernos de Pesquisa Interdisciplinar em Ciências Humanas, Florianópolis, v.15, n.106, p.179-201, 2014.

THOMPSON, John B. The media and modernity. a social theory of the media. Palo Alto: Stanford University Press, 1995.

TÖNNIES, Ferdinand. Comunidad y sociedad. Buenos Aires: Losada, 1947.

TRIVIÑOS, Augusto N. S. Introdução à pesquisa em ciências sociais: a pesquisa qualitativa em educação. São Paulo: Atlas, 1987.

VAN DIJK, Teun A. El análisis crítico del discurso. Anthropos, Barcelona, v.1, n.186, p.23-36, 1999.

ZUCKERBERG, Mark. Building global community. São Francisco, 17 fev. 2017. Facebook: https://pt-br.facebook.com/zuck. Disponível em: http://bit.ly/2sSH7Yb. Acesso em: 25 abr. 2021.

Artigo recebido em 30.04.2021 e aprovado em 09.08.2021. 